\title{
Role of Refuse Derived Fuel in the Romanian industrial sector after the entrance in $\mathrm{EU}$
}

\author{
E. C. $\operatorname{Rada}^{1,2}$, M. Ragazzi ${ }^{1} \&$ T. Apostol ${ }^{2}$ \\ ${ }^{1}$ Department of Civil and Environmental Engineering, \\ Trento University, Italy \\ ${ }^{2}$ Department of Energy Production and Use, \\ Politehnica University of Bucharest, Romania
}

\begin{abstract}
On $1^{\text {st }}$ January 2007 Romania became one of the European Union members. For this reason Romania will have to comply with all the EU directives in the field of management of the environment. Presently in Romania Municipal Solid Waste (MSW) is generally landfilled without pre-treatment and without energy valorization. The entrance in the $\mathrm{EU}$ has given an important push to the industrial sectors, increasing the need of fuels. For this reason an important option regards the use of Refuse Derived Fuel (RDF) as industrial fuel. It must be pointed out that a lot of industrial authorizations have recently been given for plants using fuel oil for energy generation as methane cannot yet reach many industrial districts. RDF could be obtained in Romania using the bio-drying process with post-separation of inert fractions as the percentage of organic fraction in MSW is significant. Presently in Romania bio-drying plants for MSW are under discussion but not yet implemented.

This paper will deal with local and global environmental balances related to a partial substitution of fuel oil with RDF for industrial uses in Romania. Balances are also based on the assessment of the Romanian RDF characteristics, taking into account the result from a recent $\mathrm{PhD}$ research. The research was developed using the MSW composition from Bucharest, where many industrial districts are under construction around the city. The scenarios presented regard the use of RDF obtained, taking into account the future development of the Romanian MSW composition and the implementation of selective collection. The scenarios concern both the use of RDF in co-combustion as a partial substitute of coal and pet-coke, and in co-generation plants for steam and electricity production in industrial sites. Also we consider the role of the agencies for the environmental control in Romania.
\end{abstract}

Keywords: bio-drying, industrial fuel, $L H V, R D F$, Romania. 


\section{Introduction}

On the $1^{\text {st }}$ of January 2007 Romania became one of the European Union members. The European Association Agreement stipulates that Romanian development policies must be guided by the principle of sustainable development and take full account of environmental considerations. For this reason Romania began to implement the EU principles on waste management trying to put, in the first place, waste prevention, in the second one recycling and energy generation, and in the last one disposal of waste with no recovery of either materials and/or energy. Romania implemented in 2005 the final version of the landfill directive 1999/31/EC and completed in the same year the pathway for the adoption of the directive $2000 / 76 / \mathrm{EU}$ on the incineration and coincineration of waste (ANP [1]).

The technologies who are attracting a considerable interest are the Mechanical Biological Treatment (MBT) and Biological Mechanical Treatment (BMT), in particular aimed to energy generation. To this concern a one stream option of BMT could be preferred to a two stream option of MBT as the first one could put to zero the need of landfill volumes. A typical one stream option is based on the bio-drying process (the core of the system is a biological process followed by mechanical post-treatments without streams to be landfilled). A typical two stream option is based on the concept of sieving (originating two streams) and on the bio-stabilisation of the undersieve (the oversieve is treated to be transformed in RDF but with a significant amount of refuse to be landfilled; also the role of the stabilized material is controversial in terms of disposal).

The Romanian waste has a high organic fraction content (about 50\% in urban areas) and for this reason the bio-drying process could be developed successfully (Rada et al. [2-4]). The final material, named generally Refuse Derived Fuel (RDF), after a refining stage can be sent to coal fired power stations or to cement kilns for partially substituting coal and pet-coke.

The refuse derived fuel from municipal solid waste (MSW) and its utilization is viewed in Romania as a strategic component of an integrated waste management policy because in this way the quantity of the biodegradable materials that could arrive in a landfill can be reduced as requested from the Landfill Directive from 1999/31/EC.

Regarding waste transport, Romania has until 2015 a transition period for the adoption of the EU regulations (ANP [1]).

In this paper MSW is assumed synonymous of residual MSW in the present scenario as selective collection is near to zero in Romania.

\section{Romanian industry and waste}

Since 2006 a part of the Romanian industry has begun to support and apply an environment policy putting on the first place the reduction of atmospheric pollution, the ecologic products production and the co-combustion of waste for saving natural resources. 
A good example is the one of the Holcim cement factory, one of the most important Romanian plants, that has obtained the ISO 14001 certification (Holcim [5]).

Another important step that the Romanian industrial sector made was the one of a good partnership with the waste sector. Presently the waste used in the industrial sector as alternative fuel is exhaust oil, sludge, used tires, refuses of the wood sector, paper and also some waste from the chemical industry. Generally the use of these fuels is limited to the cement sector.

However, in this paper it will be presented an option for using the Romanian Refuse Derived Fuel obtained from the Municipal Solid Waste bio-drying.

\section{Romanian MSW}

\subsection{MSW bio-drying and RDF - present scenario}

The Romanian waste has a high organic fraction content (about 50\%) and for this reason the bio-drying process was chosen and applied at pilot scale for two weeks (Rada et al. [2,4]) with an input representative of the present MSW.

Presently in Romania the municipal solid waste selective collection is at the experimental stage, but the aim of the Romanian waste sector is to implement the selective collection at national level until 2017 using European, Romanian and private funds.

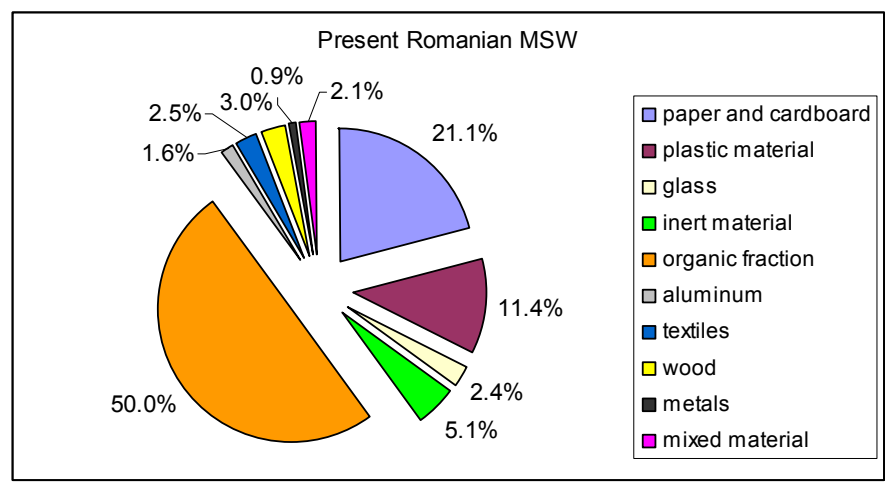

Figure 1: $\quad$ Present Romanian MSW composition.

The composition of the present Romanian MSW is shown in Figure 1. Data can be assumed representative of Bucharest. The percentage of each fraction of MSW is calculated taking into account that presently selective collection is implemented in practice only for PET, iron and paper.

The Lower Heating Value (LHV) dynamics of the present Romanian MSW, bio-dried material and RDF during the bio-drying treatment are reported in Figure 2, (Rada et al. [6,7]). It must be underlined that the biodried material and LHV increase of RDF after two weeks is respectively around $30 \%$ and $44 \%$. This is not 
an energy increase because it must be taken into account that the available mass of fuel is lower after the process. The process allows "concentrating" the initial energy with a contemporary consumption of electrical energy. Generally the energy available at the end of the process is about 3\% lower than the initial one (Rada et al. [6,7]), apart from the electricity needs that changes depending on the adopted technology.

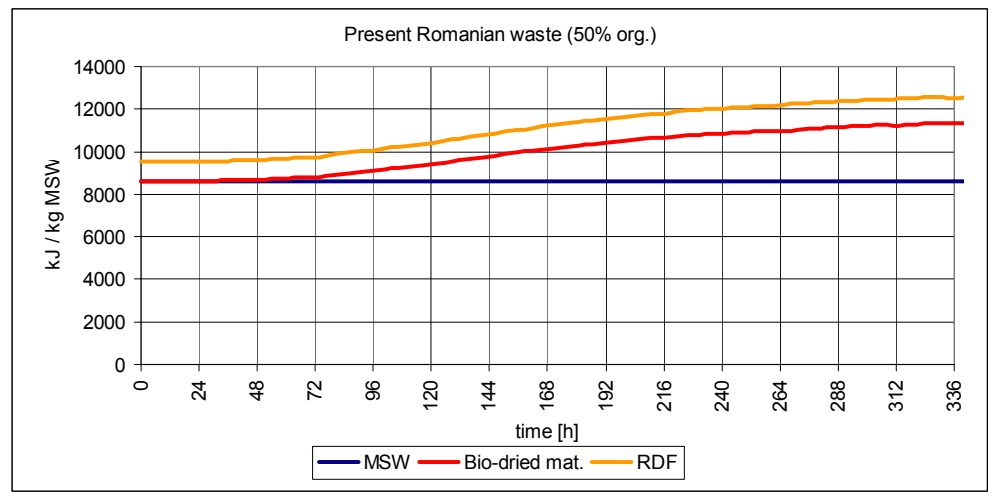

Figure 2: $\quad$ Present LHV dynamics during the bio-drying process.

\subsection{MSW bio-drying and RDF - future scenario}

The implementation of the principle of waste management in the European Union will change the characteristics of the Romanian MSW. Anyway, in spite of the aim to avoid an increase of MSW generation, we must take into account that the future per-capita production of MSW will increase. In the future scenario we have assumed that the only fractions that will increase will be the packaging ones with a triplication of the amounts. In the meanwhile we will see a development of the efficiencies of selective collection. Presently we can see that the pilot-experiences are mainly related to plastics, paper, metals and secondarily glass and wood. For the future scenario we have assumed that apart from those fractions (separately collected with an efficiency of 50\%), the selective collection will affect only a small percentage of the organic fraction. The percentage of organic fraction interested for the selective collection future scenario has been assumed as $5 \%$ as related only to green waste to be diverted from the present co-disposal with MSW. The resulting residual MSW is presented in Figure 3.

In Figure 4 the dynamics of the future Romanian residual MSW, the bio-dried material and RDF generable from this future waste are presented. For the calculation of those, the selective collection implementation and the increase of a part of MSW fractions (thanks to the expected economic development) were taken into account. 


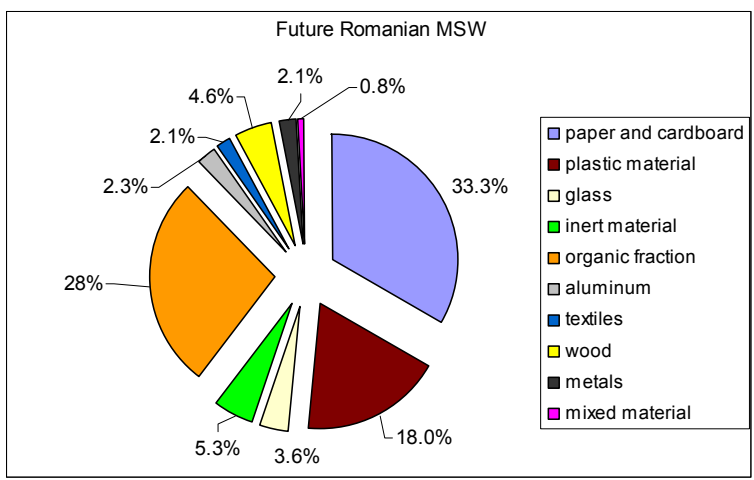

Figure 3: $\quad$ Future Romanian MSW composition.

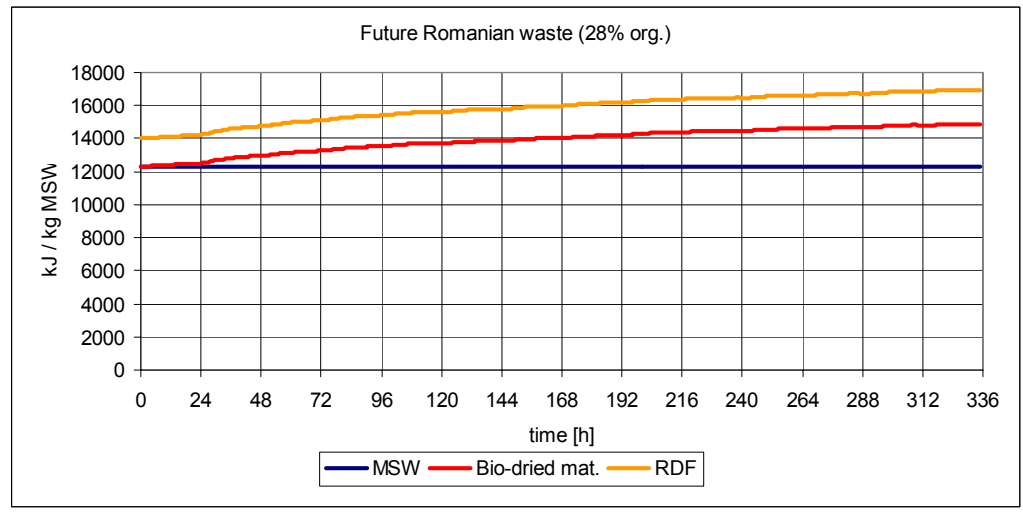

Figure 4: $\quad$ Future LHV dynamics during the bio-drying process.

Moreover, it must be underlined for the future Romanian MSW scenario that the biodried material and the RDF lower heating value increase (after two weeks) is respectively around $21 \%$ and $38 \%$.

It is clear that an extensive application of the EU principles can affect also the collection of the domestic organic fraction, but if we take into account the characteristics of the Romanian urbanisation, the organisation skills, the economy aspects, we can set a future scenario as presented. Moreover, this scenario is studied for a town where the industrial sector is very developed and than where in the short period it can be implemented a strategy based on RDF generation. The choice of a bio-dryer affects the following choices in terms of selective collection strategies, as we must "guarantee" an adequate percentage of organic fraction in the residual MSW. If we do not do that, we could have problems in the operation of the biological reactor (Rada et al. [9,11]). 


\section{Global and local balances}

One of the most important parameters regarding the global environmental balance is the $\mathrm{CO}_{2}$ emission factor referred to a unit of energy. It is clear that the $\mathrm{CO}_{2}$ measurable in the bio-drying air is the biogenic one (Rada et al. [8,9]) but the operation of a bio-drier needs electricity, with an indirect generation of $\mathrm{CO}_{2}$. A deeper approach should take into account the emission of $\mathrm{N}_{2} \mathrm{O}$ from bio-drying, but its role does not change the overall results as explained in (Rada et al. [9]). Additionally a correct balance must take into account both the $\mathrm{CO}_{2}$ from RDF combustion and the $\mathrm{CO}_{2}$ from RDF production. To this concern, only a part of $\mathrm{CO}_{2}$ from RDF combustion comes from not renewable sources, as MSW and so RDF are partially biomass.

The case taken into account is the one related to $\mathrm{CO}_{2}$ emitted using $1 \mathrm{GJ}$ coming from coal or pet-coke or fuel oil or lignite used in industrial plants compared to one $1 \mathrm{GJ}$ from RDF. The $\mathrm{CO}_{2}$ emission factors for the selected conventional fuels are taken from the literature (IPPC [10]). The $\mathrm{CO}_{2}$ emission factor for RDF is assessed taking into account the plastics content in the present and future Romanian waste $\left(\mathrm{CO}_{2}\right.$ from biodegradable fractions combustion is not taken into account). Moreover the production of RDF is related to an electric consumption depending on the characteristics of MSW (pre-treatment, biodrying process, post-treatment) (Rada et al. [6,11]). The $\mathrm{CO}_{2}$ emissions related to the used electrical energy have been referred to a Romanian thermal power plant.

In Figure 5, a comparison of emission factors is presented. The advantages of using present and future RDF from Romanian waste is clear.

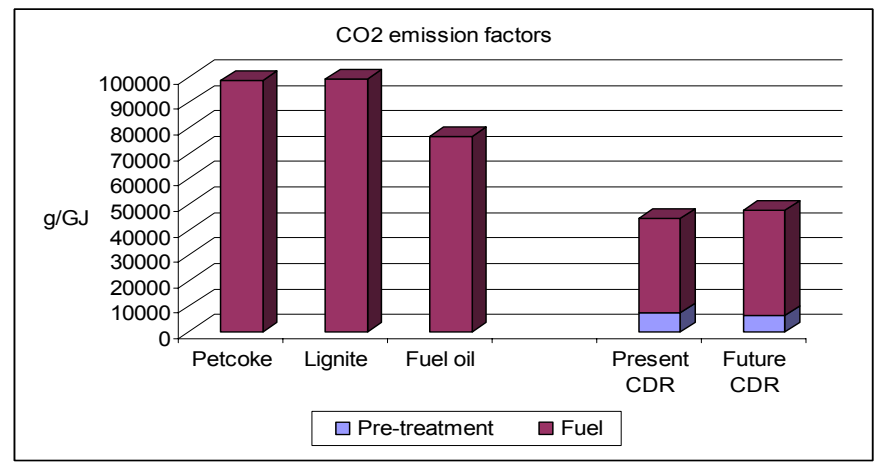

Figure 5: $\quad$ Comparison between $\mathrm{CO}_{2}$ emission factors.

The fuel substitution has another advantage: if we do not product RDF we could suppose that MSW will be sent to a sanitary landfilling. Romania can postpone MSW pre-treatment before landfilling until 2017. The biogas that could be generated gives a significant $\mathrm{CO}_{2}$ emission factor. Indeed only a part of biogas can be collected, about 50\%. The emitted biogas has a $\mathrm{CH}_{4}$ content of about $60 \%$. In terms of green-house gas equivalence we must take into account 
that methane is 21 times more impacting than $\mathrm{CO}_{2}$ (IPPC [10]). As a consequence we can assess an emission factor from MSW landfilling (always expressed as $\mathrm{g}_{\mathrm{CO} 2} / \mathrm{GJ}$ of energy in the fuel/waste) that can reach the same order of magnitude than the ones of conventional fuels. If we produce RDF we put to zero this contribution on the global balance.

Concerning local balances, a question could be related to the expected variation of emissions for instance of heavy metals. An answer could be related to the content of heavy metals in RDF compared to the one of conventional industrial fuel. To this concern, in Figure 6 data on heavy metals in German RDF and coal are reported. It is clear that for some heavy metals the environmental balance could be even better using RDF (Herhof [12]).

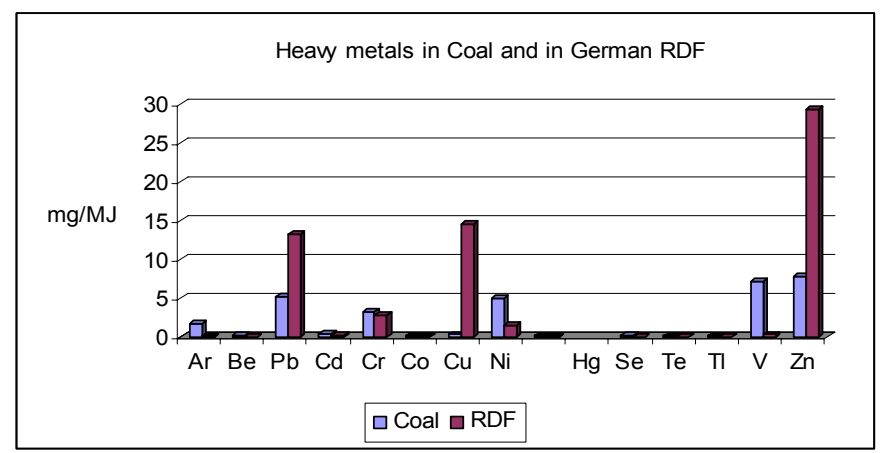

Figure 6: Comparison coal and German RDF concerning heavy metals.

Concerning the co-generation plants for steam and electricity production in industrial sites for internal uses, a problem to be faced with is the compatibility of RDF with the existing burner: for instance RDF cannot substitute a liquid fuel in a system designed only for that. As a consequence the strategy based on RDF use should be clear from now in Romania as a number of new industrial plants are under design thanks to the attraction of foreign investments.

Another aspect regards the role of the agencies for the environmental control in Romania in order to guarantee local impact adequately low. A network already exists. Some agencies already manage a few monitoring stations. The implementations of databases on industrial emissions are in progress, but the data presently available are basically self-certified from the industry. An additional problem that could be faced with is a possible overloading of activities as in this period a lot of EU directives that have been adopted must be enforced.

\section{Conclusions}

Some considerations can be taken from the present paper:

- $\quad$ the present Romanian MSW is suitable for an efficient bio-drying aimed to RDF generation;

- $\quad$ RDF can be an interesting substitute of conventional fuels in the industry; 
- global environmental balances can slightly vary depending on the characteristics of the MSW.

- $\quad$ RDF can be an alternative to the present use of landfilling;

- an adequate local impact must be guaranteed supporting a correct development of the activities of the local environment agencies.

What must be taken into account is that in a Romanian scenario it could be more favorable a strategy based on a decentralization of the energy exploitation of MSW (based on RDF) as it could lower the capital costs.

\section{References}

[1] ANP, www.anp.ro

[2] Rada E. C., Ragazzi M., Panaitescu V., Apostol T. An example of technology transfer: Why Municipal Solid Waste bio-drying? Proc. of the International Energy - Environment Conference CIEM 2005, pp. 7.467.51, 2005. Editura Universul Energiei, 2005.

[3] Rada E. C., Ragazzi M., Panaitescu V., Apostol T. Experimental characterization of Municipal Solid waste bio-drying. Proc. of $3 \mathrm{rd}$ International Conference on Waste Management and the Environment, Vol. 92, pp. 295-302. www.witpress.com.

[4] Rada E. C., Ragazzi M., Apostol T., Panaitescu V. Critical analysis of high moistures MSW bio-drying: the Romanian case study. Proc. of $2^{\text {nd }}$ International Symposium MBT 2007: Mechanical-biological treatment and automatic waste sorting technology, pp. 440-451, 2007

[5] Holcim, www.holcim.ro

[6] Rada E. C., Franzinelli A., Taiss M., Ragazzi M., Panaitescu V., Apostol T. Lower heating value dynamics during municipal solid waste bio-drying. Environmental Technology, vol. 28, pp. 463-469, 2007.

[7] Rada E. C., Ragazzi M., Panaitescu V., Apostol T. Energy from waste: the role of bio-drying. Stintific Buletin (Ro), seria C: Electrical Engineering, vol 67, nr. 2, pp. 69-76, 2005.

[8] Rada E. C., Ragazzi M., Panaitescu V., Apostol T. Some research perspective on emissions from bio-mechanical treatments of municipal solid waste in Europe. Environmental Technology, Vol. 26, Nr.11, pp. 1297-1302(6), 2005.

[9] Rada E. C., Ragazzi M., Fabbri L., Panaitescu V., Apostol T. Life Cycle Analisis applicata alla bioessiccazione: aspetti ambientali. Rifiuti Solidi, Vol. XX, N.3, pp. 183-190, 2006.

[10] IPCC/OECD/IEA Revised 1996 IPCC Guidelines for National Greenhouse Gas Inventories. 1997

[11] Rada E. C., Ragazzi M., Fabbri L., Panaitescu V., Apostol T. Life Cycle Analisis applicata alla bioessiccazione: aspetti energetici. Rifiuti Solidi, Vol. XX, N.2, pp. 89-97, 2006.

[12] Herhof, www.herhof.de 